\title{
RECONHECIMENTO DAS VARIEDADES GEOGRÁFICAS DO ESPANHOL POR ESTUDANTES DA “ELE” DA ESLOVÁQUIA, REPÚBLICA CHECA E POLÔNIA
}

\author{
RECONOCIMIENTO DE LAS VARIEDADES GEOGRÁFICAS DEL \\ ESPAÑOL POR PARTE DE ESTUDIANTES DE ELE DE ESLOVAQUIA, \\ REPÚBLICA CHECA Y POLONIA
}

\author{
SPANISH GEOGRAPHICAL VARIETIES RECOGNITION BY SFL \\ STUDENTS FROM SLOVAKIA, CZECH REPUBLIC AND POLAND
}

\author{
Radka SVETOZAROVOVÁ ${ }^{1}$
}

\begin{abstract}
RESUMO: Este trabalho estuda a identificação e categorização das variedades geográficas do espanhol por estudantes da "ELE" das Seções Bilíngues da Eslováquia, República Checa e Polônia. Além disso, são discutidos os possíveis fatores que influenciam este reconhecimento, bem como os imaginários coletivos e protótipos no caso de cada variedade. Para a coleta de dados, foram utilizadas pesquisas e gravações do projeto PRECAVES XXI. Depois de analisar as respostas dos participantes, verificamos que as variedades mais fáceis de identificar eram castelhana, rioplatense, andaluza e mexicana, enquanto as outras (canária, caribenha, andina e chilena) têm um nível de reconhecimento muito baixo. Além disso, verifica-se que os imaginários se alteram de acordo com a variedade, por isso cada uma delas funciona de forma independente.
\end{abstract}

PALAVRAS-CHAVE: Variedades de espanhol. Espanhol como língua estrangeira. Identificação de variedades. Imaginários coletivos. PRECAVES XXI.

RESUMEN: En el presente trabajo se estudia la identificación y la categorización de las variedades geográficas del español por parte de alumnos de ELE procedentes de las Secciones Bilingües de Eslovaquia, República Checa y Polonia. Además, se discuten los posibles factores que influyen en este reconocimiento, al igual que los imaginarios colectivos y los prototipos en caso de cada variedad. Para la recogida de datos, se emplean la encuesta y las grabaciones del proyecto PRECAVES XXI. Una vez analizadas las respuestas de los participantes, pudimos comprobar que las variedades más fáciles de identificar fueron la castellana, la rioplatense, la andaluza y la mexicana, mientras que las demás (canaria, caribeña, andina y chilena) cuentan con un grado de reconocimiento muy bajo. Además, se comprueba que los imaginarios varían dependiendo de la variedad, por lo que cada una de ellas presenta un funcionamiento independiente.

PALABRAS CLAVE: Variedades del español. Español como lengua extranjera. Identificación de las variedades. Imaginarios colectivos. PRECAVES XXI.

${ }^{1}$ Universidade de Granada (UGR), Granada - Espanha. Doutoranda no programa Línguas, Textos e Contextos. ORCID: https://orcid.org/0000-0002-5077-1220. E-mail: svetozarovova@gmail.com 
ABSTRACT: The present paper examines the identification and categorization of Spanish geographical varieties by SFL students from the Bilingual Sections of Slovakia, the Czech Republic and Poland. In addition, the factors that may influence this recognition are discussed, as well as the social imaginaries and prototypes for each variety. The PRECAVES XXI project survey and recordings are used for data collection. After analyzing the participants' responses, we found that the varieties that were easiest to identify were Castilian, Rioplatense, Andalusian and Mexican, while the others (Canarian, Caribbean, Andean and Chilean) showed a very low level of recognition. Furthermore, it was found that the imaginaries vary depending on the variety, showing that each one of them works independently.

KEYWORDS: Spanish varieties. Spanish as a foreign language. Identification of the varieties. Social imaginaries. PRECAVES XXI.

\section{Introdução e estado da questão}

O estudo do reconhecimento e identificação de variedades geográficas é relativamente recente e ainda há poucas pesquisas dedicadas a esse tema. Podemos mencionar, por exemplo, Williams, Garrett e Coupland (1999), Clopper e Pisoni (2004) e Baker, Eddington e Nay (2009) para inglês; Van Bezooijen e Gooskens (1999) para inglês e holandês; Gooskens (2004) para o norueguês e Cunningham-Andersson (1996) para o sueco. No caso do espanhol, temos a contribuição de Díaz-Campos e Navarro-Galisteo (2009). Além disso, deve-se mencionar que a maioria das obras publicadas no âmbito do projeto PRECAVES XXI (Projeto para o Estudo de Crenças e Atitudes para Variedades Espanholas no Século XXI) possuem uma ou mais seções dedicadas ao reconhecimento de variedades (ver Boletim de Filologia, 2018).

Por outro lado, esta é uma área ainda pouco conhecida no caso de falantes não nativos. Podemos mencionar Cunningham-Andersson (1996), que se concentra no reconhecimento de variedades de suecos por falantes nativos de inglês, ou Schoonmaker-Gates (2018) que faz um estudo semelhante para espanhol, também com falantes nativos de inglês.

Embora no campo hispânico só conheçamos uma dessas contribuições, consideramos que este é um tema particularmente interessante, uma vez que os falantes do espanhol como língua estrangeira (ELE) podem oferecer outro ponto de vista, justamente porque não é a língua materna deles. Portanto, neste trabalho propomos realizar um estudo piloto, no qual analisamos até que ponto os alunos da ELE, das Seções Bilíngues Espanholas da Eslováquia, República Checa e Polônia, são capazes de identificar corretamente as variedades geográficas do espanhol a partir das gravações oferecidas pelo PRECAVES XXI e estabelecer qual área ou região é percebida como o protótipo de cada um deles. 
Acreditamos que tal estudo pode fornecer dados interessantes sobre como e se esses alunos percebem a variação geolinguística de uma linguagem que não é deles e que pode ser útil não apenas para a análise de suas atitudes e crenças, mas também para o planejamento e modelo das aulas de ELE.

\section{Considerações teóricas}

\section{A percepção da variação linguística em estudantes de ELE}

O fato de o espanhol ser uma língua policêntrica causou controvérsia ao escolher materiais para as aulas de ELE, fazendo a seguinte pergunta: Que espanhol ensinar? No entanto, deve-se lembrar que tais questões, bem como o estudo de atitudes e crenças em relação a fenômenos geolinguísticos, fazem parte do fato de que os falantes são capazes de perceber a variação geográfica da língua. Como cita Caravedo, "a percepção do falante está preparada para capturar e adquirir tanto os aspectos que variam quanto aqueles que não variam em sua comunidade e no período em que ele é capaz de viver" (2018, p. 72) ${ }^{2}$. Sua percepção dessa variação, no entanto, não precisa necessariamente corresponder à classificação proposta pelos cientistas.

Por outro lado, e relacionado ao contato que um falante (nativo ou estrangeiro) tem com as variedades, Moreno Fernández (2017, p. 9-12) divide os usuários de uma língua de acordo com o "modelo focal", dependendo do seu grau de conhecimento disso. O primeiro grupo são os falantes "monofocais", que têm apenas um bom conhecimento de sua própria variedade, enquanto eles praticamente desconhecem os outros e só podem classificar os falantes de acordo com as grandes variedades de espanhol (por exemplo, América Latina). Os bifocais, por outro lado, têm uma compreensão mais profunda da realidade dialetal de uma região diferente da sua (por exemplo, pelo contato com seus falantes ou por residência). E por último, um alto-falante "multifocal" é aquele que teria um conhecimento profundo da realidade dialetal de um número indefinido de variedades. No entanto, como o próprio autor menciona, o maior grupo é monofocal. A questão, no entanto, seria o que acontece no caso do grupo de estrangeiros, especialmente dada a complexidade da questão da " variedade própria " neste caso.

Uma das causas pelas quais é problemático estabelecer qual é a percepção de um falante ELE da situação dialetal do espanhol é, talvez, o que Fernández Martín menciona (2014, p. 31 e 36-38), ou seja, que o geralmente ensinado na sala de aula da ELE é muitas

2“la percepción del hablante está preparada para captar y adquirir tanto los aspectos que varían como los que no varían en su comunidad y en el periodo en que le toca vivir" 
vezes a linguagem "artificial" (em oposição à linguagem natural ou dialetal). Suspeitamos que essa falta de contato com a língua real pode fazer com que um estrangeiro desconheça a realidade dialetal do espanhol e, portanto, se torne incapaz de identificar corretamente o que ouve. No entanto, consideramos que isso não necessariamente impede que se perceba as diferenças entre as diferentes variedades, mesmo que não se conheça completamente. Nesse sentido, vale ressaltar a importância da formação e do contato com diferentes tipos de discurso, o que permite ao orador conhecer a variação de uma língua (CARAVEDO, 2018, p. 77).

Por fim, ao realizar um estudo de reconhecimento das variedades é essencial lidar com o tema de sua categorização pelos usuários de uma língua. Como argumenta Garcia (1998, p. 11), "para as os lingüistas as línguas são concebidas como somas ou intersecções de seus traços, para os falantes quase sempre como protótipos". ${ }^{3} \mathrm{Em}$ linhas gerais, como menciona Moreno Fernández (2001, p. 3), "a percepção da variação linguística - e não esqueçamos que nem toda variação é conscientemente percebida - responde a um processo de categorização baseado na aprendizagem discriminatória". ${ }^{4}$ No entanto, essa categorização pode ser feita de diferentes formas. Segundo o mesmo autor (2001, p. 3), existem três propostas teóricas que visam explicar como os falantes classificam variedades: teoria dos traços, teoria do exemplar e teoria do protótipo. No caso do primeiro, a "presença ou ausência de uma característica particular é responsável por um elemento que está sendo atribuído a uma determinada categoria" (MORENO FERNANDEZ, 2001, p. 3). ${ }^{5}$ Por exemplo, o rioplatense espanhol pode ser identificado graças ao seu yeísmo reestruturado. A teoria do exemplar "sustenta que a categorização dos objetos depende da memória de um exemplar (caso específico) e da categoria à qual pertence" (MORENO FERNANDEZ, 2001, p. 4). ${ }^{6}$ Ou seja, um falante só pode reconhecer uma variedade porque conhece amigos, professores, cantores etc. que pertencem a ela e "falam igual". Finalmente, de acordo com a teoria do protótipo, "um protótipo é definido como um conjunto abstrato de características comumente associadas com membros de uma categoria" (MORENO FERNÁNDEZ, 2001, p. 5). ${ }^{7}$ Assim, o espanhol

\footnotetext{
3 “para el lingüista las lenguas se conciben como sumas o intersecciones de rasgos, para el hablante casi siempre como prototipos".

4 "la percepción de la variación lingüística - y no olvidemos que no toda la variación se percibe conscientemente - responde a un proceso de categorización basado en un aprendizaje discriminatorio".

5 "para el lingüista las lenguas se conciben como sumas o intersecciones de rasgos, para el hablante casi siempre como prototipos".

6 "sostiene que la categorización de objetos depende del recuerdo de un ejemplar (caso concreto) y de la categoría a la que pertenece"

7 "un prototipo se define como un conjunto abstracto de características comúnmente asociadas con los miembros de una categoría"
} 
canário poderia ser identificado por toda a sua aspiração do implosivo -/s/ e do uso da palavra "guagua"8, que a diferenciaria de outras variedades com aspiração de consoantes finais.

\section{A situação dialetal do espanhol}

Embora existam várias propostas da divisão dialetal do espanhol, neste trabalho seguimos a proposta de Moreno Fernández (2019), já que é a que gerencia o PRECAVES XXI, cuja pesquisa aplicamos em nosso estudo. Assim, este autor diferencia oito grandes áreas do espanhol. Por um lado, teríamos as áreas espanholas, às quais o castelhano (centro e norte da Espanha), o andaluz (principalmente na Andaluzia, embora para os propósitos deste trabalho, e sobretudo por causa da proximidade fonética, incluímos aqui as falas de transição de Múrcia e Extremadura) e canário (ilhas canárias). Por outro lado, teríamos as áreas hispano-americanas. Pertencem a elas o espanhol mexicano ou centro-americano (México, Guatemala, Honduras, El Salvador e Nicarágua), o caribenho (Antilhas, terras costeiras continentais em contato com o Mar do Caribe, Costa Rica, Panamá, a maior parte da Venezuela e a parte costeira da Colômbia), o andino (a maior parte da Colômbia, parte da Venezuela, Equador, Peru e Bolívia), o chileno (Chile) e o austral (Paraguai, Uruguai e Argentina; ao contrário de Moreno Fernández, usaremos neste trabalho a denominação espanhol rioplatense $)^{9}$.

Por fim, vale ressaltar também a existência de dois grandes grupos de variedades: o conservador (espanhol, mexicano ou centro-americano e andino) e o inovador (espanhol andaluz, canário, caribenho, chileno e rioplatense). A diferença entre eles seria que, enquanto o primeiro tende a reter certos traços fonéticos (como a manutenção de consoantes de palavra final, consoantes intervocálicas e grupos consonantais cultos, a pronúncia não aspirada do /x/ y não africada $/ t^{\circ} /$ e a distinção entre /ante/ e $/ 1 /$, como entre $/ 0 /$ e $/ \mathrm{j} /$ ), este último tende a enfraquecê-los ou perdê-los (como enfraquecimento, aspiração ou perda de consoantes de palavra final, enfraquecimento de consoantes de entrelaçamentos, simplificação de grupos cultos, aspiração de /x/, surdricação de $/ \mathrm{t}^{\circ} /$, neutralização de líquidos e yeismo) (MORENO FERNÁNDEZ, 2019, p. 83).

${ }^{8}$ Com o significado de ônibus.

${ }^{9}$ Para obter mais informações sobre a divisão territorial das áreas espanholas e suas características, consulte Moreno Fernández (2019). 


\section{Objetivos e metodologia}

\section{Objetivos}

O principal objetivo deste trabalho é estudar até que ponto os alunos da ELE são capazes de identificar as variedades geográficas do espanhol a partir de uma gravação, quais protótipos existem ao seu redor, como os categorizam e, de certa forma, quais características de cada um deles podem influenciar essa categorização.

\section{Coleta de dados}

Para realizar essa anaálise usamos ou levantamos PRECAVES XXI. Trata-se de um projeto que visa estudar como atitudes e a crenca dos falantes em variedades espanholas e consistem em uma pesquisa an'nima, online (acessada por um código único), baseada na técnica de pares falsos ou matched-guise. Embora seja uma ferramenta que nos permita coletar uma grande quantidade de dados, neste trabalho só sudaremos ou reconhecimento das variedades, então isso explicaremos simplesmente como o correspondente vê. Para uma metodologia completa, consulte Cestero y Paredes (2018).

Quanto à estrutura do questionário, consiste em duas partes: a primeira, na qual o aluno deve preencher seus dados sociográficos, e a segunda, na qual ouve, uma após uma, fitas de estímulo de cerca de 3 minutos de duração e pertencentes ao padrão culto das oito variedades mencionadas acima. Cada um deles aparece duas vezes, uma vez em discurso espontâneo (todos os falantes falam sobre o mesmo tema: problemas de trânsito nas grandes cidades) e outro em discurso lido (o texto é sempre o mesmo e seu tema principal é a vivência). Cada um deles permite uma única reprodução. Por fim, deve-se notar que, dependendo do código que o entrevistado recebe, ao longo da pesquisa você ouvirá gravações com uma voz masculina ou de uma mulher.

Após ouvir cada gravação, o participante deve responder a uma série de perguntas relacionadas à avaliação (direta e indireta) da variedade e seu reconhecimento. De todos estes, neste trabalho só estamos interessados no seguinte: a) Aponte um aspecto da pronúncia que você particularmente gostou; b) Aponte um aspecto da pronúncia que o perturbou especialmente; c) De qual país ou região você acha que a pessoa está falando? Deve-se notar que, em todas as perguntas, o estrevistado responde livremente e sem qualquer apoio.

Deve-se mencionar que esta pesquisa não foi projetada para o estudo do reconhecimento ou categorização das variedades, mas sim para o estudo de sua avaliação. Portanto, não nos permite obter informações sobre os traços específicos que o respondente reconheceu na variedade, pois pode identificá-los, mas não os valoriza negativamente ou positivamente. No entanto, esta seção pode nos dar alguma ideia de quais características são 
impressionantes. A escolha desse método em nosso trabalho baseia-se principalmente na pesquisa que oferece uma riqueza de dados que podem ser usados em um estudo subsequente de atitudes e crenças. Apesar disso, consideramos que é uma ferramenta suficientemente válida para uma primeira abordagem deste problema.

\section{Amostra e variáveis}

A amostra com a qual trabalhamos é composta por 57 estudantes (16 homens e 41 mulheres) da ELE, das Seções Bilíngues ${ }^{10}$ (SSBB) da Eslováquia, República Checa e Polônia ${ }^{11}$. Sua composição pode ser vista na Tabela 1. No momento da pesquisa, alguns dos alunos ainda estavam fazendo seus estudos secundários em um dos SSBB, enquanto outros já estavam matriculados em um bacharelado ou mestrado (filológico ou não filológico). A decisão de trabalhar com uma amostra específica é baseada no seguinte:

a) O ensino de espanhol na SSBB é feito através do tema Língua Espanhola e Literatura e, no caso de cada seção, há um currículo oficial que estabelece seu conteúdo e planejamento $^{12}$. A análise desses documentos sugere que um aluno desses SSBBs deve ter algum conhecimento sobre a situação dialetal da língua, embora sem especificar os conteúdos específicos, por isso geralmente são os próprios professores que os selecionam (o currículo não estabelece qual divisão geográfica e quais características devem ser ensinadas). Acreditamos que nossa análise pode fornecer dados valiosos sobre o conhecimento real dos alunos sobre a variação da linguagem geográfica que podem ser maiores para o desenvolvimento ou modificação do currículo futuro.

b) Os alunos dessas seções recebem treinamento tanto na ELE quanto em outras disciplinas ministradas em espanhol. Além disso, sabemos que eles entram em contato com falantes nativos, não apenas por causa das atividades culturais que geralmente são organizadas nesses centros, mas também porque o Ministério da Educação e Formação Profissional (MEFP) convoca anualmente vagas para professores com nacionalidade espanhola dentro do programa Professores em seções bilíngues de espanhol em escolas da Europa Central, Europa Oriental e China para lecionar nessas seções.

${ }^{10}$ Para obter mais informações sobre o SSBB, consulte MEFP (s.f. $\left.{ }^{b}\right)$.

${ }^{11}$ Os SSBBs mencionados não são exclusivos desses três países. Sua escolha é devido à experiência, que completou seus estudos secundários em um dos SSBBs na Eslováquia, de modo que seu conhecimento poderia ser útil na interpretação dos resultados.

${ }^{12}$ Currículo de lengua y literatura españolas. Cursos III, IV y V. Secciones Bilingües de Eslovaquia, 2016; Currículo de Lengua y Literatura Españolas. Secciones Bilingües en la República Checa, 2007 y Currículo de Lengua y Literatura Españolas. Secciones Bilingües de español. Polonia, s.f. ${ }^{a}$ 
c) O nível de idioma desses alunos geralmente é alto o suficiente para que eles entendam a pesquisa aplicada ${ }^{13}$.

Tabela 1 - Composição da amostra

\begin{tabular}{|c|c|c|c|c|c|c|c|}
\hline \multirow[b]{4}{*}{ País de origem } & \multicolumn{6}{|c|}{ Estudos } & \multirow[b]{4}{*}{ Total } \\
\hline & \multirow{2}{*}{\multicolumn{2}{|c|}{ Pré-universitários }} & \multicolumn{4}{|c|}{ Universitarios } & \\
\hline & & & \multicolumn{2}{|c|}{ Não filológicos } & \multicolumn{2}{|c|}{ Filológicos } & \\
\hline & H & $\mathbf{M}$ & $\mathbf{H}$ & M & H & $\mathbf{M}$ & \\
\hline Eslováquia & 8 & 7 & 2 & 8 & 0 & 4 & 29 \\
\hline República Checa & 1 & 2 & 4 & 5 & 1 & 3 & 16 \\
\hline Polônia & 0 & 0 & 0 & 2 & 0 & 10 & 12 \\
\hline Total & 9 & 9 & 6 & 15 & 1 & 17 & 57 \\
\hline
\end{tabular}

Fonte: elaboração própria

A amostragem foi feita acidentalmente não probabilísticamente, ou pela técnica "bola de neve", portanto, o número de participantes por caixa é desigual. Como mais mulheres do que homens participaram do estudo (o que ocorre porque, geralmente, há mais mulheres estudando na SSBB), essa variável não é levada em conta. O mesmo vale para a idade, já que todos os entrevistados têm entre 16 e 26 anos. Se os participantes fossem divididos em duas faixas etárias, esse corte corresponderia aos estudos variáveis, que são levados em conta, bem como o país de origem dos entrevistados. Embora seja verdade que várias pesquisas demonstraram a importância da residência em uma região onde a variedade estudada é falada ao identificá-la (por exemplo, CLOPPER; FLATNI, 2004), e sabemos a importância do contato com falantes nativos, neste estudo não temos dados suficientes para incluir essas variáveis $^{14}$.

Em suma, as variáveis que são levadas em conta são as seguintes:

a) Variáveis típicas da gravação: variedade (castelhana, andaluz, canária, centroamericana ou mexicana, caribenha, andina, chilena, rioplatense); discurso (espontâneo, lido); voz (masculino, feminino);

${ }^{13}$ A duração da formação nos SSBBs acima mencionados pode variar dependendo do país, embora geralmente seja de 5 anos, com ensino de ELE desde o primeiro curso. Por razões linguísticas, no caso de estudantes que ainda estão fazendo seus estudos secundários, é essencial que eles pertençam aos últimos cursos, quando sua proficiência em espanhol geralmente equivale a B2-C1. Uma vez que os currículos da SSBB não especificam qual nível deve ser ensinado em cada curso, não podemos fornecer informações precisas sobre o nível real de nossos participantes. Deve-se notar que, na SSBB da Eslováquia, o aluno, após concluir seus estudos, recebe um certificado estadual equivalente ao $\mathrm{C} 1$, emitido pelo centro.

${ }^{14}$ Para a análise de dados, o pacote estatístico IBM SPSS 20 foi utilizado A utilização da análise quantitativa deve-se a que, no total, obtivemos 876 respostas no total, uma vez que cada um dos 57 entrevistados avalia 16 gravações (aos quais deve ser subtraído de casos não respondidos). 
b) Variáveis do próprio entrevistado: país de origem (Eslováquia, República Checa, Polônia); estudos (universitários pré-universitários, não-filológicos, estudos universitários filológicos).

\section{Resultados}

\section{Identificação das variedades}

Primeiro, analisamos o grau e o tipo de identificação de variedades, para as quais usamos as respostas para a pergunta De que país ou região você acha que a pessoa está falando? O grau de sucesso é dividido em quatro categorias: acerto exato (ao responder "Sevilla" ou Andaluzia para a variedade andaluz), acerto genérico (por exemplo: "América Latina" para uma variedade americana), erro (por exemplo: "Andaluzia" para a variedade mexicana, mas também "Hispanoamerica" para uma variedade espanhola) e, claro, não sabe/não responde. Como pode ser visto na Tabela 2, o sucesso exato é relativamente baixo (22,3\%), enquanto em quase metade dos casos o entrevistado não está correto $(49,66 \%)$.

Tabela 2 - Identificação geral das variedades

\begin{tabular}{|l|c|c|}
\hline \multicolumn{3}{|c|}{ Grau de reconhecimento } \\
\hline & $\mathbf{N}$ & $\%$ \\
\hline Acerto exato & 193 & $22,03 \%$ \\
\hline Acerto genérico & 142 & $16,21 \%$ \\
\hline Erro & 435 & $49,66 \%$ \\
\hline NS/NC/Outros & 106 & $12,10 \%$ \\
\hline Total & 876 & $100,0 \%$ \\
\hline
\end{tabular}

Fonte: elaboração própria

Por outro lado, estamos interessados em saber, em caso de sucesso exato, quais variedades são mais facilmente reconhecidas. Os resultados apresentados na Figura 1 mostram que as variedades com maior grau de reconhecimento são castelhana e rioplatense, o que provavelmente está relacionado ao fato de terem dois traços únicos: a distinção sistemática entre o /s/ e o /o/ no caso do primeiro e do "yeismo" reestruturado no caso do segundo. Em seguida, a modalidade andaluz também tem um percentual considerável, embora inferior aos anteriores. Por fim, destaca o baixo reconhecimento do espanhol caribenho, canário, chileno e andino, por isso parece que os entrevistados não estão familiarizados com essas formas dialetais. 
Figura 1 - Identificação exata das variedades

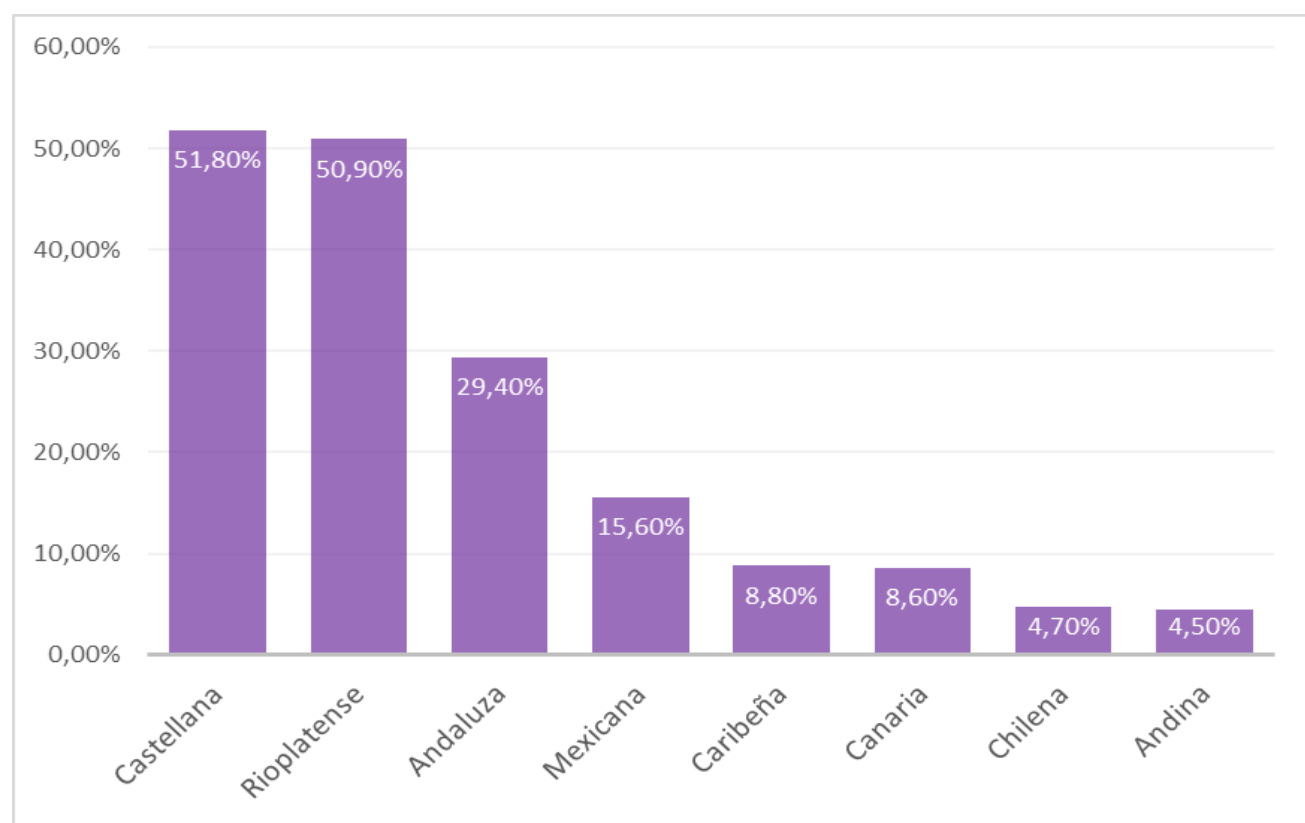

Fonte: elaboração própria

\section{Categorização das variedades}

Embora a Figura 1 nos permita saber quais variedades são mais reconhecíveis, o que não nos mostra é a distribuição do acerto genérico, erro e NS/NC para cada variedade. Esses dados podem ser especialmente úteis para determinar como as diferentes modalidades geográficas do espanhol são categorizadas e qual foco está sendo aplicado em cada caso. Esta distribuição é mostrada na Tabela 3.

Tabela 3 - Identificação desagregada de variedades

\begin{tabular}{|c|c|c|c|c|c|c|c|c|c|c|}
\hline \multirow[b]{3}{*}{ Variedades } & \multicolumn{10}{|c|}{ Grau de reconhecimento } \\
\hline & \multicolumn{2}{|c|}{ Acerto exato } & \multicolumn{2}{|c|}{ Genérico } & \multicolumn{2}{|c|}{ Erro } & \multicolumn{2}{|c|}{ NS/NC/Outros } & \multicolumn{2}{|c|}{ Total } \\
\hline & $\mathrm{N}$ & $\%$ & $\mathrm{~N}$ & $\%$ & $\mathrm{~N}$ & $\%$ & $\mathrm{~N}$ & $\%$ & $\mathrm{~N}$ & $\%$ \\
\hline Castelhana & 59 & $51,8 \%$ & 29 & $25,4 \%$ & 16 & $14,0 \%$ & 10 & $8,8 \%$ & 114 & $100 \%$ \\
\hline Andaluza & 32 & $29,4 \%$ & 22 & $20,2 \%$ & 41 & $37,6 \%$ & 14 & $12,8 \%$ & 109 & $100 \%$ \\
\hline Canária & 9 & $8,6 \%$ & 19 & $18,1 \%$ & 61 & $58,1 \%$ & 16 & $15,2 \%$ & 105 & $100 \%$ \\
\hline Mexicana & 17 & $15,6 \%$ & 20 & $18,3 \%$ & 52 & $47,7 \%$ & 20 & $18,3 \%$ & 109 & $100 \%$ \\
\hline Caribenha & 10 & $8,8 \%$ & 17 & $15,0 \%$ & 76 & $67,3 \%$ & 10 & $8,8 \%$ & 113 & $100 \%$ \\
\hline Andina & 5 & $4,5 \%$ & 18 & $16,4 \%$ & 73 & $66,4 \%$ & 14 & $12,7 \%$ & 110 & $100 \%$ \\
\hline Chilena & 5 & $4,7 \%$ & 5 & $4,7 \%$ & 82 & $77,4 \%$ & 14 & $13,2 \%$ & 106 & $100 \%$ \\
\hline Rioplatense & 56 & $50,9 \%$ & 12 & $10,9 \%$ & 34 & $30,9 \%$ & 8 & $7,3 \%$ & 110 & $100 \%$ \\
\hline
\end{tabular}

Fonte: elaboração própria 
No entanto, nenhuma das tabelas acima nos permite realmente saber o que acontece em caso de erro, ou, em outras palavras, como a identificação errada é distribuída em cada variedade e se essa distribuição segue algum padrão específico. Para isso, é possível levar em conta que existem dois focos possíveis da análise. No primeiro caso, a variedade ouvida baseia-se na análise e nas respostas oferecidas pelos entrevistados analisados. Pelo contrário, no segundo caso, começamos a partir das respostas e analisamos a variedade que os entrevistados realmente ouviram. Este estudo de identificação reversa é principalmente de nosso interesse porque uma modalidade dialetal pode ter um grau de reconhecimento muito alto, mas isso pode ser devido aos participantes atribuirem essa resposta a todas as modalidades ouvidas. Por outro lado, o estudo de casos não identificados corretamente pode nos dizer se o aluno está errado em relação a alguma variedade específica, por exemplo, se ele permanece dentro do mesmo grupo (conservador ou inovador) ao qual o modo dialetal ouvido pertence. A Tabela 4 mostra a distribuição completa das respostas por gravação (apenas casos de acerto exato e erro são levados em conta, de modo que os percentuais não correspondem às tabelas acima).

Tabela 4 - Identificação de variedades: gravações e respostas

\begin{tabular}{|c|c|c|c|c|c|c|c|c|c|c|c|c|c|c|c|c|c|}
\hline \multirow{3}{*}{$\begin{array}{l}\text { Variedade } \\
\text { escutada }\end{array}$} & \multicolumn{16}{|c|}{ Respostas } & \\
\hline & \multicolumn{2}{|c|}{ Castelhana } & \multicolumn{2}{|c|}{ Andaluza } & \multicolumn{2}{|c|}{ Canaria } & & \multicolumn{2}{|c|}{ Mexicana } & \multicolumn{2}{|c|}{ Caribenha } & \multicolumn{2}{|c|}{ Andina } & \multicolumn{2}{|c|}{ Chilena } & \multicolumn{2}{|c|}{ Rioplatense } \\
\hline & $\mathbf{N}$ & $\%$ & $\mathbf{N}$ & $\%$ & $\mathbf{N}$ & $\%$ & & $\mathrm{~N}$ & $\%$ & $\mathrm{~N}$ & $\%$ & $\mathrm{~N}$ & $\%$ & $\mathrm{~N}$ & $\%$ & $\mathrm{~N}$ & $\%$ \\
\hline Castelhana & 59 & 30,9 & 7 & 5,9 & 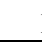 & 6 & & 1 & 1,8 & 1 & 4,0 & 1 & 2,4 & 0 & 0,0 & 2 & 2,8 \\
\hline Andaluza & 24 & 12,6 & 32 & 26,9 & 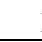 & 6 & & 3 & 5,3 & 1 & 4,0 & 5 & 11,9 & 0 & 0,0 & 1 & 1,4 \\
\hline Canaria & 16 & 8,4 & 20 & 16,8 & 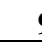 & 60 , & & 4 & 7,0 & 3 & $12,($ & 6 & 14,3 & 2 & 11,8 & 0 & 0,0 \\
\hline Mexicana & 16 & 8,4 & 5 & 4,2 & ( & 0, & & 17 & 29,8 & 0 & 0,0 & 7 & 16,7 & 6 & 35,3 & 3 & 4,2 \\
\hline Caribenha & 18 & 9,4 & 23 & 19,3 & 2 & 13 , & & 5 & 8,8 & 10 & 40,0 & 7 & 16,7 & 2 & 11,8 & 5 & 7,0 \\
\hline Andina & 25 & 13,1 & 4 & 3,4 & ( & 0 , & & 18 & 31,6 & 3 & 12,0 & 5 & 11,9 & 0 & 0,0 & 2 & 2,8 \\
\hline Chilena & 18 & 9,4 & 22 & 18,5 & 2 & 13 , & & 6 & 10,5 & 7 & 28,0 & 6 & 14,3 & 5 & 29,4 & 2 & 2,8 \\
\hline Rioplatense & 15 & 7,9 & 6 & 5,0 & ( & 0 , & & 3 & 5,3 & 0 & 0,0 & 5 & 11,9 & 2 & 11,8 & 56 & 78,9 \\
\hline Total & 191 & 100 & 119 & 100 & 1 & 10 & & 57 & 100 & 25 & 100 & 42 & 100 & 17 & 100 & 71 & 100 \\
\hline
\end{tabular}

Fonte: elaboração própria

A análise na Tabela 4 revela que, de fato, a frequência com que as variedades que aparecem nas respostas não é a mesma. Além disso, pode-se observar que todos eles operam de forma independente. Assim, a variedade que mais aparece nas respostas é o castelhano, e embora seja verdade que na maioria dos casos é corretamente atribuído à gravação, também é muito frequente sua atribuição incorreta para outras variedades. Além disso, parece que isso não segue nenhum padrão concreto. Isso nos levaria a pensar que ele é usado como uma 
espécie de "curinga" quando não se sabe qual modo geográfico está sendo ouvido, mas, por outro lado, quando o participante ouve a gravação do Centro-Norte espanhol, quase sempre o identifica corretamente. Parece, portanto, que sua alta porcentagem de sucesso na identificação não se deve ao acaso.

A segunda variedade mais comum nas respostas é a Andaluzia. Neste caso, não temos mais uma porcentagem tão alta de reconhecimento. Se olharmos para o número de vezes que essa resposta foi incorretamente atribuída a outra modalidade dialetal, podemos ver que esta atribuição é mantida principalmente dentro do grupo inovador, ao qual o andaluz pertence, exceto no caso da rioplatense espanhola, que comentaremos mais tarde. Por outro lado, quando se ouve andaluz, é bastante comum identificá-lo corretamente ou, caso contrário, como castelhano. Muito raramente outra variedade aparece nas respostas.

A variedade canariana aparece nas respostas quase exclusivamente quando se trata dela. Pelo contrário, ao ouvir, a maioria das respostas são "Andaluz" (ambas são inovadoras) e castelhana (ambas são espanholas). Com o espanhol caribenho um padrão muito semelhante se repete (exceto que este não é da Espanha).

A resposta "mexicana" é atribuída tanto a esta mesma variedade quanto à andina, e aquela com uma frequência muito semelhante. Essas respostas dificilmente são atribuídas a outras variedades. Quando, por outro lado, o espanhol mexicano é ouvido, é comum responder ou "mexicano" ou "castelhano" (ambos são conservadores). No entanto, o interessante é que a resposta "andina" dificilmente está no questionário (e se assim for, nenhum padrão concreto é seguido), mas quando você ouve espanhol andino, a maioria das respostas são "catelhanas" ou "mexicanas". Ou seja, parece que os participantes reconhecem a semelhança entre as três variedades mencionadas (todas são conservadoras) e a semelhança entre mexicano e andino (as duas únicas variedades conservadoras hispânico-americanas), mas este par é o mexicano que é mais representativo.

A variedade chilena dificilmente aparece nas respostas e em sua análise não encontramos nenhum padrão peculiar, exceto que, quando é ouvida, as respostas majoritárias são "Andaluz" e "castelhana".

No caso do rioplatense, segue-se um padrão muito claro: ele só é respondido quando é realmente ouvido, e quando é ouvido, é corretamente identificado.

\section{Fatores que influenciam no reconhecimento}


Quanto às variáveis da gravação (discurso e voz), ambas são significativas. A Tabela 5 mostra o reconhecimento das variedades de acordo com o discurso (espontâneo ou lido). O teste 2 de Pearson definiu a significância dessa variável na p-0,000064, com discurso espontâneo facilitando o sucesso exato, enquanto no caso da leitura da fala é geralmente respondida genericamente ou NS/NC (tabela 5). Essa análise parece lógica quando se considera que a fala espontânea favorece o aparecimento de traços dialetais, o que facilita a identificação da variedade.

Tabela 5 - Acerto no reconhecimento de acordo com a fala

\begin{tabular}{|c|c|c|c|c|c|c|c|c|c|c|}
\hline \multirow{3}{*}{ Discurso } & \multicolumn{10}{|c|}{ Acerto no reconhecimento } \\
\hline & \multicolumn{2}{|c|}{ Acerto } & \multicolumn{2}{|c|}{ Erro } & \multicolumn{2}{|c|}{ Genérico } & \multicolumn{2}{|c|}{ NS/NC/Outros } & \multicolumn{2}{|c|}{ Total } \\
\hline & $\mathbf{N}$ & $\%$ & $\mathbf{N}$ & $\%$ & $\mathbf{N}$ & $\%$ & $\mathbf{N}$ & $\%$ & $\mathbf{N}$ & $\%$ \\
\hline Espontâneo & 122 & $27,8 \%$ & 216 & $49,2 \%$ & 58 & $13,2 \%$ & 43 & $9,8 \%$ & 439 & $100,0 \%$ \\
\hline Lido & 71 & $16,2 \%$ & 219 & $50,1 \%$ & 84 & $19,2 \%$ & 63 & $14,4 \%$ & 437 & $100,0 \%$ \\
\hline
\end{tabular}

Fonte: elaboração própria

A variável de voz também foi significativa $(\mathrm{p}-0,00)$, onde o erro é mais comum para a voz do homem, enquanto as respostas genéricas e NS/NC são mais frequentes no caso da voz feminina. No caso do acerto não há quase nenhuma diferença (tabela 6).

Tabela 6 - Acerto no reconhecimento segundo a voz

\begin{tabular}{|c|c|c|c|c|c|c|c|c|c|c|}
\hline \multirow{3}{*}{ Voz gravada } & \multicolumn{10}{|c|}{ Reconhecimento de acerto } \\
\hline & \multicolumn{2}{|c|}{ Acerto } & \multicolumn{2}{|c|}{ Erro } & \multicolumn{2}{|c|}{ Genérico } & \multicolumn{2}{|c|}{ NS/NC/Outros } & \multicolumn{2}{|c|}{ Total } \\
\hline & $\mathbf{N}$ & $\%$ & $\mathbf{N}$ & $\%$ & $\mathbf{N}$ & $\%$ & $\mathbf{N}$ & $\%$ & $\mathbf{N}$ & $\%$ \\
\hline Homem & 98 & $22,3 \%$ & 261 & $59,5 \%$ & 54 & $12,3 \%$ & 26 & $5,9 \%$ & 439 & $100,0 \%$ \\
\hline Mulher & 95 & $21,7 \%$ & 174 & $39,8 \%$ & 88 & $20,1 \%$ & 80 & $18,3 \%$ & 437 & $100,0 \%$ \\
\hline
\end{tabular}

Fonte: elaboração própria

Quanto às variáveis do próprio entrevistado, foram manipuladas para que a técnica de amostragem afetasse o resultado o mínimo possível. Como quase todos os participantes na Polônia pertencem ao nível universitário filológico, removemos esses participantes da análise dos estudos variáveis. Para o conjunto final de dados (estudantes tchecos e eslovacos), essa variável é significativa (p-0,000207), com o nível universitário filológico facilitando o acerto exato. Os resultados são mostrados na Tabela 7. 
Tabela 7 - Acerto no reconhecimento de acordo com a formação dos entrevistados

\begin{tabular}{|l|c|c|c|c|c|c|c|c|c|c|}
\hline \multirow{2}{*}{\begin{tabular}{c}
\multirow{2}{*}{$\begin{array}{c}\text { Estudos dos } \\
\text { participantes }\end{array}$} \\
\cline { 2 - 12 }
\end{tabular}} & \multicolumn{2}{|c|}{ Acerto } & \multicolumn{2}{|c|}{ Erro } & \multicolumn{2}{|c|}{ Genérico } & \multicolumn{1}{c|}{$\begin{array}{c}\text { NS/NC/Outr } \\
\text { os }\end{array}$} & \multicolumn{2}{c|}{ Total } \\
\cline { 2 - 11 } & N & \% & N & $\%$ & N & $\%$ & N & $\%$ & N & $\%$ \\
\hline Secundários & 46 & $17,6 \%$ & 136 & $52,1 \%$ & 31 & $11,9 \%$ & 48 & $18,4 \%$ & 261 & $100,0 \%$ \\
\hline $\begin{array}{l}\text { Universitários não } \\
\text { filólogos }\end{array}$ & 67 & $20,4 \%$ & 171 & $52,1 \%$ & 67 & $20,4 \%$ & 23 & $7,0 \%$ & 328 & $100,0 \%$ \\
\hline $\begin{array}{l}\text { Universitários } \\
\text { filólogos }\end{array}$ & 80 & $27,9 \%$ & 128 & $44,6 \%$ & 44 & $15,3 \%$ & 35 & $12,2 \%$ & 287 & $100,0 \%$ \\
\hline
\end{tabular}

Fonte: elaboração própria

Finalmente, para estabelecer a importância do país variável de origem, do conjunto anterior, também eliminamos os alunos em nível pré-universitário (uma vez que na Eslováquia temos 15 alunos deste nível, enquanto na República Checa apenas 3). Para este conjunto de dados, a variável país de origem é significativa (p-0,0135), embora essa diferença apareça principalmente em acerto genérico, não em exato/erro, como mostrado na Tabela 8.

Tabela 8 - Acerto em reconhecimento de acordo com a origem do entrevistado

\begin{tabular}{|c|c|c|c|c|c|c|c|c|c|c|}
\hline \multirow{3}{*}{ País de origem } & \multicolumn{10}{|c|}{ Reconhecimento de acerto } \\
\hline & \multicolumn{2}{|c|}{ Acerto } & \multicolumn{2}{|c|}{ Erro } & \multicolumn{2}{|c|}{ Genérico } & \multicolumn{2}{|c|}{ NS/NC/Outro } & \multicolumn{2}{|c|}{ Total } \\
\hline & $\mathbf{N}$ & $\%$ & $\mathbf{N}$ & $\%$ & $\mathbf{N}$ & $\%$ & $\mathbf{N}$ & $\%$ & $\mathbf{N}$ & $\%$ \\
\hline Eslováquia & 43 & $19,3 \%$ & 110 & $49,3 \%$ & 57 & $25,6 \%$ & 13 & $5,8 \%$ & 223 & $100,0 \%$ \\
\hline Republica Checa & 48 & $23,9 \%$ & 108 & $53,7 \%$ & 27 & $13,4 \%$ & 18 & $9,0 \%$ & 201 & $100,0 \%$ \\
\hline
\end{tabular}

Fonte: elaboração própria

\section{Imaginários e protótipos no reconhecimento e categorização de variedades}

Como mencionado acima, os participantes poderiam responder livremente qual área ou região eles acreditam que o falante é. Portanto, nesta seção estamos interessados em realizar uma análise detalhada dessas respostas, a fim de estabelecer quais áreas ou regiões são consideradas as mais prototípicas para cada modalidade dialetal. Além disso, são estudadas as características destacadas pelos participantes para cada um deles (embora por razões explicadas na seção Metodologia, a análise dessa resposta é apenas para orientação). A Tabela 9 apresenta um resumo de cada variedade e da região que resulta mais prototípica ao 
identificá-la. Os dados são apresentados abaixo, levando em conta apenas os casos de sucesso exato.

Tabela 9 - Protótipos na identificação das variedades

\begin{tabular}{|l|c|}
\hline \multicolumn{1}{|c|}{ VARIEDADES } & REGI $\tilde{O} \mathbf{O}$ \\
\hline Castelhana & Madrid \\
\hline Andaluza & Andalucía \\
\hline Canaria & Islas Canarias \\
\hline Mexicana/Centroamericana & México \\
\hline Caribenha & Cuba \\
\hline Andina & Colombia \\
\hline Chilena & Chile \\
\hline Rioplatense & Argentina \\
\hline
\end{tabular}

Fonte: elaboração própria

\section{O espanhol castelhano}

A resposta majoritária de longe é "Madrid" (19 respostas), seguida por "centro da Espanha" (9), "norte da Espanha (8), "Castela e Leão" (4), "Valencia" (4), "Castela la Mancha" (3), "Castela" (Castilla" (Castilla 3), "centro norte da Espanha" (2), "Catalunha" (2), "Castela/Aragão" (1), "La Rioja" (1), "Astúrias" (1), "Zaragoza" (1) e "Toledo" (1).

Entre as características destacadas estão a pronúncia fricativa de /x/, a não omissão de consoantes e a pronúncia implosiva -/s/, pronúncia do -/d/ fim da palavra como /-/, a aspiração do -/k/ final ${ }^{15}$, a pronúncia apicoalveolar do /s/ e a distinção entre /s/ e /s//.

\section{O espanhol andaluz}

A resposta mais frequente é "Andaluzia" (14), seguida por "Sul da Espanha" (8), "Norte da Espanha" (2), "Granada" (2), "Málaga" (1), "Cádiz" (1), "Extremadura" (1), "Múrcia" (1), "Sul da Espanha, América" (1) e "Sudeste da Espanha" (1).

Os destaques foram a desafricação do /t $/$ /, a omissão e aspiração de consoantes, incluindo também -/s/ implosivo, aspiração de /x/, simplificação de grupos cultos, mas também distinção entre $/ \mathrm{s} / \mathrm{e} / \mathrm{o} /{ }^{16}$.

${ }^{15}$ Nenhum caso concreto é especificado; assumimos que o entrevistado pode se referir à simplificação de grupos cultos.

${ }^{16}$ Este fato é impressionante quando levamos em conta que em espanhol andaluz a distinção do chiado não é sistemática e a desafricação do /t $\mathrm{f} /$ não é geralmente associada ao padrão culto, embora até certo ponto seja percebida na gravação. 


\section{O espanhol canário}

Neste caso, apenas as "Ilhas Canárias" (8) ou "Ilhas Canárias/ Cuba" (1) são respondidas. Quanto às características, destacam-se a aspiração da pronúncia (/s/ implosiva) das consoantes sonoras oclusivas, aspiração de /x/ e aspiração em geral, seseo, pronúncia muito suave de /t $\int$ / e o uso da palavra "guagua".

\section{O espanhol mexicano ou centroamericano}

A resposta prototípica é "México" (17), embora em menor grau também apareça "México, Puebla" (1), "Mexico Center, D.F." (1), "América do Sul, México" (1) ou "México, América Central" (1).

As características mencionadas foram a manutenção do -/s/ implosivo, alongamento vocálico, seseo, fechamento de algum hiato em ditongos (/ea/ ( /ia/), não aspiração (em geral), omissão de algumas consoantes implosivas, aspiração de /x/ e o uso de "isso" e "bem".

\section{O espanhol caribenho}

As respostas incluem "Cuba" (4), "Venezuela" (3), "Caribe" (2) e "Cuba/República Dominicana" (1). Destaca a nasalização, aspiração em geral, especialmente da implosiva -/s/, vocalização de /b/, omissão do -/d/ final e -/d/- intervocálico, aspiração do /x/ e do osso.

\section{O espanhol andino}

As únicas respostas coletadas são "Colômbia" (2), "Bogotá/outra parte da Colômbia" (1), "Bolívia" (1) e "Peru" (1). Os destaques incluem a aspiração de /x/, prolongamento de /ante/ no final da palavra, pronúncia oclusiva do /b/ intervocálico e seseo.

\section{O espanhol chileno}

Em todos os casos, a resposta é "Chile" (5), e as características coletadas foram as seguintes: aspiração do /x/, omissão de -/s/ e consoantes finais e seseo.

\section{O espanhol rioplatense}

A resposta majoritária é de longe "Argentina" (40), seguida por "Uruguai" (7), "Rio da Prata" (4), "Argentina/Uruguai" (3), "Argentina/Paraguai" (1) e "Paraguai" (1).

Entre as características marcantes estão a omissão de consoantes, uma entonação peculiar, aspiração, seseo, e yeísmo reestruturado. 


\section{Conclusões}

Neste trabalho realizamos um estudo piloto sobre o reconhecimento e categorização de variedades geográficas de espanhol por estudantes da ELE dos SSBBs da Eslováquia, República Checa e Polônia.

Embora o reconhecimento global tenha sido relativamente baixo $(22,03 \%$ apenas de acerto exato; $38,24 \%$ com acerto genérico), consideramos que é um número bastante significativo, dado que estes são falantes estrangeiros. Além disso, pudemos ver que eles utilizam seu conhecimento linguístico na identificação de variedades, o que é demonstrado não apenas em respostas livres, mas também no fato de que o discurso espontâneo facilita o reconhecimento de variedades (em frente à leitura da fala). Além disso, pudemos ver que o treinamento filológico também é importante ao identificá-los corretamente, o que provavelmente ocorre porque os alunos têm formação mais linguística que os ajuda a realizar essa tarefa. Quanto à categorização e protótipos das diferentes modalidades dialetais do espanhol, pudemos verificar que cada uma delas funciona quase de forma independente, embora existam padrões claros em sua identificação. Por exemplo, a resposta "castelhano" é usada como uma espécie de "curinga", pois é respondida com muita frequência para todas as variedades. Esses dados podem mostrar que, para nossos entrevistados, essa modalidade geográfica é o protótipo do espanhol em geral. Por outro lado, a resposta "andaluz" também foi muito frequente, mas, principalmente, para variedades inovadoras. Na verdade, parece que os entrevistados consideram essa variedade como o protótipo do espanhol inovador. Em relação a este último, deve-se mencionar que parece que os entrevistados percebem a diferença entre espanhol conservador e inovador, uma vez que, com exceção da variedade castela, eles geralmente permanecem dentro do grupo correspondente. Além disso, o espanhol mexicano e andino (duas variedades conservadoras hispânico-americanas) foram reconhecidos juntos, sendo o mexicano o mais representativo. Quanto ao rioplatense, os participantes parecem identificá-lo com muita segurança, já que raramente é respondido para outras variedades. Deve-se notar também que as modalidades canariana, caribenha e chilena parecem ser pouco conhecidas ou difíceis de categorizar.

Por outro lado, consideramos que nossa análise de imaginários e protótipos mostra que os alunos pesquisados pertencem ao grupo de falantes "monofocais", como também é comum em coletivos nativos. Apesar disso, eles não identificam simplesmente as maiores áreas da língua (Espanha vs. Hispanoamérica. América Latina), mas tendem a mencionar regiões mais específicas. 
Quanto à análise dos traços marcantes de cada variedade, estes parecem mostrar que o rioplatense é reconhecido graças ao seu yeismo reestruturado, característica não mencionada por nenhum outro. Portanto, neste caso, a teoria do traço proposto por Moreno Fernández (2001, p. 3), enquanto no resto dos casos o caráter conservador e inovador do discurso parece ser reconhecido, de modo que a teoria do protótipo provavelmente seria aplicada aqui (a teoria do espécime excluído da análise seria aplicada, uma vez que não temos informações suficientes para estudá-la).

Quanto a análise dos traços marcantes de cada variedade, estes parece mostrar que o rioplatense é reconhecido graças ao seu yeismo retruturado, característica não mencionada por nenhuma outra. Portanto, neste caso, uma teoria da característica proposta por Moreno Fernández (2001, p. 3), enquanto nos outros casos ou caráter conservador e inovador do discurso parece ser reconhecido, de modo que uma teoria do protoxicamente provavelmente seria aplicada aqui (uma teoria do exemplar excluido da análise seria aplicada, uma vez que não tende informar o suficiente para estudá-la).

Em suma, podemos concluir que os alunos da ELE percebem a variação geográfica do espanhol e, além disso, são sensíveis a ele, uma vez que não o fazem, só foram capazes de reconhecer a existência dos dois grandes grupos de variedades, conservadoras e inovadoras, mas também foram capazes de destacar com bastante precisão algumas características em cada variedade. Além disso, pudemos ver que essa sensibilidade aumenta com a formação do aluno, embora também seja importante a familiaridade que o aluno tem com todas as variedades. Por isso, consideramos que a variação geolinguística do espanhol deve fazer parte do currículo das classes ele, enfatizando que todas as principais áreas do espanhol estão representadas nos materiais didáticos.

Por fim, deve-se notar que o presente trabalho só deve ser entendido como uma primeira abordagem para este problema. Em estudos futuros, pretendemos não apenas projetar um método mais adequado para esta análise, mas também incluir mais variáveis que possam ser significativas, como o contato dos entrevistados com falantes nativos ou sua estadia em países de língua espanhola. No entanto, consideramos que os dados aqui obtidos podem ser úteis não apenas para estudos futuros de valorização e percepção das variedades, mas também para o campo do ensino do espanhol para os estrangeiros.

\section{REFERÊNCIAS}

BAKER, W.; EDDINGTON, D.; NAY, L. Dialect identification: the effects of region of origin and amount of experience. American Speech, v. 84, n. 1, p. 48-71, 2009. 
CARAVEDO, R. Variación y cambio desde una perspectiva sociocognitiva. In: CONGRESO INTERNACIONAL DE HISTORIA DE LA LENGUA ESPAÑOLA, 10., 2015. Zaragoza. Anais [...]. Zaragoza: Institución Fernando el Católico, 7-11 set. 2015. p. 67-96.

CESTERO, A. M. y PAREDES, F. Creencias y actitudes hacia las variedades cultas del español actual: el proyecto PRECAVES XXI. Boletín de Filología de la Universidad de Chile, v. 53, n. 2, p. 11-43, 2018.

CHIQUITO, A.; QUESADA PACHECO, M. Actitudes lingüísticas de los hispanohablantes hacia el idioma español y sus variantes. Bergen: University of Bergen, 2014.

CLOPPER, C. G.; PISONI, D. B. Homebodies and army brats: some effects of early linguistic experience and residential history on dialect categorization. Language Variation and Change, v. 16, n. 1, p. 31-48, 2004.

CUNNINGHAM-ANDERSSON, U. Learning to interpret sociodialectal cues. Speech, Music and Hearing: Quarterly Progress and Status Report, v. 37, n. 2, p. 155-158, 1996.

DEPARTAMENTO DE LINGÜÍSTICA. CESTERO, A. M.; F. PAREDES. (Coords.). Percepción de las variedades cultas del español: creencias y actitudes de jóvenes universitarios hispanohablantes. Monográfico del Boletín de Filología, Universidad de Chile, v. 53, n. 2, 2018.

DÍAZ-CAMPOS, M.; NAVARRO-GALISTEO, I. Perceptual categorization of dialect variation in Spanish. In: Collentine, J. et al. (Coords.). Selected proceedings of the 11th Hispanic linguistics symposium. Somerville, MA: Cascadilla Proceedings Project. 2009. p. 179-195

FERNÁNDEZ MARTÍN, P. La conciencia lingüística en el aula de ELE: lengua artificial, lengua natural y diversidad sociolingüística. Revista Internacional de Lenguas Extranjeras, n. 3, 31-61, 2014.

GARCÍA, Á. L. Los conceptos de lengua y dialecto a la luz de la teoría de prototipos. La Torre: Revista de la Universidad de Puerto Rico, v. 3, n. 7, p. 7-19, 1998.

GOOSKENS, C. How well can Norwegians identify their dialects? Nordic Journal of Linguistics, v. 28, n. 1, p. 37-60, 2005.

MINISTERIO DE EDUCACIÓN, CULTURA Y DEPORTE. Currículo de lengua y literatura españolas. Cursos III, IV y V. Secciones Bilingües de Eslovaquia. Secretaría General Técnica del MECD, Subdirección General de Información y Publicaciones, 2016.

MINISTERIO DE EDUCACIÓN Y CIENCIA, SECRETARÍA GENERAL TÉCNICA. Currículo de lengua y literatura españolas. Secciones Bilingües en la República Checa. Secretaría General Técnica. Centro de Publicaciones. Agregaduría de Educación en la República Checa, 2007. 
MINISTERIO DE EDUCACIÓN Y FORMACIÓN PROFESIONAL. (s.f.a) Currículo de Lengua y Literatura Españolas. Secciones Bilingües de español. Polonia. Disponible em: https://www.educacionyfp.gob.es/polonia/dam/jcr:54ed989c-2c84-4a96-836702459a3c551d/curriculo-l-literat2011-12.pdf. Acceso el: 15 maio 2019.

MINISTERIO DE EDUCACIÓN Y FORMACIÓN PROFESIONAL. (s.f. b). Secciones bilingües en Europa central y oriental, China y Turquía. Disponible em: http://www.educacionyfp.gob.es/en/contenidos/ba/actividad-internacional/oficinas-centroexterior/centros-docentes/seccione-bilingue-europa.html. Acceso el: 10 jun. 2019.

MORENO FERNÁNDEZ, F. Prototipos y prestigio en los modelos de español. Carabela. Modelos de uso de la lengua española, n. 50, p. 5-20, 2001.

MORENO FERNÁNDEZ, F. Variedades del español y evaluación. Opiniones lingüísticas de los anglohablantes. Informes del Observatorio/Observatory Reports, p. 1-53, 2017.

MORENO FERNÁNDEZ, F. La lengua española en su geografía: manual de dialectología hispânica. 4. ed. Madrid: Arco/Libros, 2019.

SCHOONMAKER-GATES, E. Dialect comprehension and identification in L2 Spanish: Familiarity and type of exposure. Studies in Hispanic and Lusophone Linguistics, v. 11, n. 1, p. 193-214, 2018.

VAN BEZOOIJEN, R.; GOOSKENS, C. Identification of language varieties: the contribution of different linguistic levels. Journal of language and social psychology, v. 18, n. 1, p. 3148, 1999.

WILLIAMS, A.; GARRETT, P.; COUPLAND, N. Dialect Recognition. In: PRESTON, D. R. (Coord.). Handbook of perceptual dialectology. Vol. 1). Amsterdam/Philadelphia: John Benjamins Publishing Company, 1999. p. 345-358.

\section{Como se referir a este artigo}

SVETOZAROVOVÁ, Radka. Reconhecimento das variedades geográficas do espanhol por estudantes da "ele" da Eslováquia, República Checa e Polônia. Rev. EntreLínguas, Araraquara, v. 6, n. 1, p. 146-166, jan./jun., 2020. e-ISSN: 2447-3529. DOI: https://doi.org/10.29051/el.v6i1.13318

Encaminhado em: 30/07/2019

Revisões realizadas em: 30/08/2019

Aceito em: 30/11/2019

Publicado em: 06/01/2020 
Rev. EntreLínguas, Araraquara, v. 6, n. 1, p. 146-166, jan./jun., 2020.

e-ISSN: 2447-3529.

DOI: https://doi.org/10.29051/el.v6i1.13318 